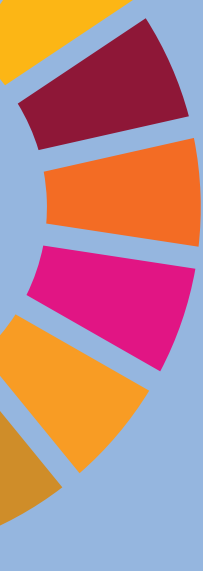

\title{
WHAT CAN ZERO HUNGER DO FOR GLOBAL HEALTH?
}

\section{¿QUÉ PUEDE HACER EL HAMBRE CERO POR LA SALUD GLOBAL?}

\author{
Estefanía Custodio Cerezales \\ Scientific Officer at the Joint Research Centre \\ of the European Commission \\ ecustodio2014@gmail.com
}

\section{ABSTRACT}

The sustainable development goal\#2 or "zero hunger" aims at ending hunger and malnutrition, and proposes five targets covering nutrition, food security, agriculture and biodiversity. Nutrition is a critical part of health, as malnutrition poses significant and direct threats to human health. Thus, tackling malnutrition can contribute to global health throughout many different pathways. This note explores some of these pathways, as well as the interlinkages of the other "zero hunger" targets and global health. Although the links between food security and nutrition and health are more straightforward, there are also bidirectional interactions between the agriculture and biodiversity-related targets and health to take into account when designing new approaches to tackle global health and zero hunger. In this note, we recommend to consider agriculture as a social determinant of health with an important role to play. Moreover, we advocate for a systemic approach that integrates health and sustainability within food systems, as proposed by the EU "From Farm to Fork" strategy.

Keywords: Zero hunger, Food security, Malnutrition, Agriculture, Biodiversity, Health

\section{RESUMEN}

El objetivo de desarrollo sostenible \#2 o "hambre cero" tiene como objetivo acabar con el hambre y la malnutrición, y para ello propone cinco metas que abarcan la nutrición, la seguridad alimentaria, la agricultura y la biodiversidad. La nutrición es parte intrínseca de la salud, pues la malnutrición tiene efectos nocivos directos sobre la salud humana. Por tanto, abordar la malnutrición beneficia también a la salud global, y puede hacerlo por distintos caminos. Esta nota explora algunos de estos caminos, así como las inter-relaciones entre las otras metas de "hambre cero" y la salud global. Aunque la relación entre seguridad 
alimentaria y nutrición con la salud parece más evidente, hay también relaciones bidireccionales entre las metas relacionadas con la agricultura y la biodiversidad y la salud, que deben tenerse en cuenta cuando se diseñan nuevas estrategias para alcanzar la salud global y el hambre cero. En esta nota, recomendamos la consideración de la agricultura como un determinante social de la salud con un papel importante que jugar. Además, promovemos el enfoque sistémico que integra la salud y la sostenibilidad de los sistemas alimentarios, tal como propone la estrategia "From Farm to Fork" de la UE.

Palabras clave: Hambre cero, Seguridad alimentaria, Malnutrición, Agricultura, Biodiversidad, Salud

Estefania Custodio works as a scientific officer at the Joint Research Centre of the European Commission conducting applied research on Nutrition and Food Security to support EC policies. Previously she worked at the National Centre of Tropical Medicine of the Instituto de Salud Carlos III conducting research on Malnutrition and Neglected Tropical diseases.

\section{INTRODUCTION}

The aim of this paper is to explore the different ways by which the Sustainable Development Goal \#2 (SDG2) or "Zero Hunger" can contribute to global health, and vice versa. For that purpose, in the first part of the document, we describe the SDG2 and its corresponding targets, and in the second part, we describe the interlinkages between each target and health.

The Sustainable Development Goal \#2 (SDG2) or "Zero hunger" aims to end hunger and all forms of malnutrition by 2030 , proposing five specific targets.

The first one, Target $2.1^{1}$, aims at ending hunger and ensuring food security for all people, and is measured by two indicators: the prevalence of undernourishment $(\mathrm{PoU})$ and the prevalence of moderate or severe food insecurity, based on the Food Insecurity Experience Scale (FIES). The PoU is a population-level indicator used to estimate the proportion of the population whose habitual food consumption is insufficient, in terms of calories, to maintain a normal and healthy life, and is used as proxy of hunger. The FIES measures the prevalence of moderate or severe food insecurity and is based on the responder's answers to questions related to food behaviours and experiences in the context of food insecurity.

The 2019 edition of the State of Food Security and Nutrition in the World report (Food and Agriculture Organization of the United Nations, 2019) estimated that 820 million people in the world suffered from hunger according to the PoU. In addition, that around 1.3 billion people experienced moderate food insecurity as measured by FIES, increasing to 2 billion people when the moderate and acute food insecurity were combined ( $26.4 \%$ of the world population).

The second target (Target 2.22) aims to end all forms of malnutrition. Malnutrition, in all its forms, comprises undernutrition (stunting, wasting and micronutrient deficiencies), as well as overweight and obesity. Target 2.2 is measured by the prevalence of stunting, wasting and overweight.

\footnotetext{
${ }^{1}$ Target 2.1 By 2030, end hunger and ensure access by all people, in particular the poor and people in vulnerable situations, including infants, to safe, nutritious and sufficient food all year round.

2 Target 2.2. By 2030 , end all forms of malnutrition, including achieving, by 2025 , the internationally agreed targets on stunting and wasting in children under 5 years of age, and address the nutritional needs of adolescent girls, pregnant and lactating women and older persons.
} 
Stunting or growth retardation is characterized by a slowing in children's growth and their failure to reach their expected height. It is the result of poor nutrition in-utero and early childhood, and it has been associated to impaired cognitive development and poor immunity to disease, among others (Dewey \& Begum, 2011). In 2019 it was estimated that 144 million, or $21 \%$ of children under 5 years of age globally, suffered from stunting (UNICEF et al., 2020) .

Wasting occurs when an individual suffers from current, severe nutritional restrictions; a recent bout of illness; inappropriate childcare practices; or, more often, a combination of these factors. It is characterised by extreme weight loss, and, in its severe form, can lead to death. The last estimations reported that 27 million children under five were wasted in 2019 , or $7 \%$ of the under 5 children globally (UNICEF et al., 2020).

Furthermore, it is estimated that 2 billion people suffer from micronutrient deficiencies, a suboptimal nutritional status caused by a lack of intake, absorption or use of one or more vitamins or minerals (2018 Global Nutrition Report: Shining a Light to Spur Action on Nutrition., 2018). However, there is limited knowledge on the overlaps with other forms of malnutrition, and the consequences for health and disease.

While undernutrition remains a great concern, overweight and obesity are rapidly increasing all over the world, including in low-and middle-income countries. In 2019, 38 million children under 5 were estimated to be overweight (UNICEF et al., 2020), as well as 340 million children and adolescents aged 5 to 19 , and more than $30 \%$ of the adult population, with increasing trends over the past two decades (2018 Global Nutrition Report: Shining a Light to Spur Action on Nutrition., 2018) .

Whereas undernutrition is 10 times more prevalent in developing countries, overweight and obesity prevail in wealthier countries at rates of up to 5 times higher than in poorer countries (2020 Global Nutrition Report: Action on Equity to End Malnutrition., 2020).

The Target $2.3^{3}$ is focused in increasing the productivity and income of small-scale food producers, in particular women, indigenous peoples, family farmers, pastoralists and fishers, through secure and equal access to land and other productive resources and inputs.

Around $84 \%$ of the circa 600 million farms in the world are small-scale farms, with extensions less than 2 hectares, and they operate only around $12 \%$ of all agricultural land (Lowder SK et al., 2019). Smallholders play an essential role in ensuring food security and nutrition, and they are themselves often affected by food insecurity and malnutrition. Around $80 \%$ of the world's poor and food insecure live in rural areas and most of the rural poor are small-scale family food producers (Committee on World Food Security, 2016).

Women play an important role within the smallholders system, as they produce between 60 and 80 per cent of the food in most developing countries. However, they have more difficulties than men in gaining access to resources such as land, credit or other productivity enhancing inputs and services (IFAD \& UNEP, 2013). Among smallholders there are around 350 million indigenous peoples who conserve many different crop varieties and livestock breeds but in many places have limited rights to land and resources (Maas Wolfenson KD, 2013).

\footnotetext{
${ }^{3}$ Target 2.3. By 2030, double the agricultural productivity and incomes of small-scale food producers, in particular women, indigenous peoples, family farmers, pastoralists and fishers, including through secure and equal access to land, other productive resources and inputs, knowledge, financial services, markets and opportunities for value addition and non-farm employment.
} 
The aim of Target $2.4^{4}$ is to ensure sustainable food systems and resilient agricultural practices that help maintain ecosystems.

The current agricultural practices are undermining the ecosystems supporting today's global food system, through overuse and agricultural pollution. Thus, the capacity of ecosystems to generate sustainable yields is diminishing which can have negative impacts on food security and poverty reduction (IFAD \& UNEP, 2013).

Moreover, food systems today face many other complex and rising challenges like continued population growth, urbanization, climate change and increased pressure on natural resources (land, water, biodiversity) (Willett et al., 2019). Concurrently, present food systems result in different forms of malnutrition as described under Target 2.2, and affect food and nutrition security indirectly through their economic and health impacts, including: low income and difficult livelihoods for many food producers and precarious and difficult working conditions for many farm and food workers, among others.

Thus, more sustainable food systems are needed that ensure sufficient food production while also safeguarding human and environmental health as well as socio-economic standards (High Level Panel of Experts on Food Security and Nutrition, 2019).

The last target of SDG2 (Target 2.5) ${ }^{5}$ puts the emphasis in maintaining the genetic diversity of seeds and promoting the fair and equitable sharing of benefits arising from the utilization of genetic resources and the traditional knowledge associated with it.

Since the 1900s, some 75 per cent of crop diversity has been lost from farmers' fields, as farmers worldwide have left their multiple local varieties for genetically uniform, high-yielding varieties, and $30 \%$ of livestock breeds are at risk of extinction (FAO, 2004). Besides, the global population of wild species has fallen by $60 \%$ over the last 40 years, and 1 million species are at risk of extinction (European Commission, 2020a).

Biodiversity loss, including of critical crop pollinators, and loss of soil quality will both have substantial impacts on global agricultural outputs (like fruit and vegetables) supply and thereby may result in a significant impact on population's health and nutritional status (Dangour AD et al., 2017).

Moreover, biodiversity can strengthen the resilience of agricultural systems by maintaining and enhancing the diversity of species, the functional diversity and the genetic resources to sustain overall agroecosystem biodiversity in time and space at field, farm and landscape scales (High Level Panel of Experts on Food Security and Nutrition, 2019).

\footnotetext{
${ }^{4}$ Target 2.4: By 2030, ensure sustainable food production systems and implement resilient agricultural practices that increase productivity and production, that help maintain ecosystems, that strengthen capacity for adaptation to climate change, extreme weather, drought, flooding and other disasters and that progressively improve land and soil quality.

${ }^{5}$ Target 2.5: By 2020, maintain the genetic diversity of seeds, cultivated plants and farmed and domesticated animals and their related wild species, including through soundly managed and diversified seed and plant banks at the national, regional and international levels, and promote access to and fair and equitable sharing of benefits arising from the utilization of genetic resources and associated traditional knowledge, as internationally agreed
} 


\section{INTERLINKAGES BETWEEN ZERO HUNGER AND HEALTH}

\subsection{HUNGER AND HEALTH}

The impact of food insecurity and hunger on health is mainly mediated by poor nutrition, as inadequate dietary intake is one of the immediate causes of malnutrition, in turn sustained by food insecurity as one of the main underlying causes (UNICEF, 1990).

Food insecurity is associated with undernutrition in low income countries and with overweight and obesity among low socioeconomic groups in middle-high and high income countries (Food and Agriculture Organization of the United Nations, 2019).

In addition, there are other effects of hunger on health not necessarily mediated by poor nutrition but most likely by the anxiety and other stress-related symptoms of living in food insecure households. Several studies have associated food insecurity with adult's depression and anxiety and with children's mental disorders (Melchior $M$ et al., 2012). The undertake of negative strategies like alcohol or tobacco to cope with food insecurity emotional distress also has negative consequences on health (Chilton M \& Booth S, 2007).

Household and community food insecurity fall with health into a vicious cycle as food insecurity hinders the community capacities to produce food, or to generate income to purchase food, perpetuating the cycle of food insecurity, malnutrition and disease.

\subsection{MALNUTRITION AND HEALTH}

Nutrition is a critical part of health and development, as malnutrition, in every form, presents significant threats to human health. It is estimated that malnutrition is the underlying cause of $45 \%$ of global deaths in children below 5 years of age (WHO, 2020).

Stunting is associated in the short term with increased morbidity and mortality from infectious diseases (Prendergast \& Humphrey, 2014) and in the long term with reduced physical, neurodevelopmental and economic capacity and an elevated risk of metabolic disease into adulthood (WHO, 1995).

Wasting or acute malnutrition is associated with increased vulnerability to infections and is a strong predictor of mortality. As the severity of the condition increases the body becomes more and more limited to respond to stresses such as infection, thus severely acute malnutrition subjects can rapidly become extremely ill, requiring intensive medical and nurse care to recover (Collins et al., 2006).

Overweight and obesity in adults are major risk factors for non-communicable diseases like diabetes, hypertension, coronary heart disease, or certain types of cancer, which in turn results in high demands on health systems (WHO, 2000). Also childhood overweight increases the risk of early onset of diabetes and hypertension (Darnton-Hill et al., 2004).

The interlinkages between malnutrition and infectious disease at the micro level follow a circular pattern, as malnutrition impairs immunological response increasing vulnerability to infection and repetitive infectious episodes impact nutrition through different pathways (increased energetic needs due to fever, malabsorption of nutrients due to damaged intestinal tract, etc.). Moreover, at community level the vicious circle is continued as the loss of energy derived from disease and malnutrition reduces the productivity 
capacity of community members to provide for their families, hindering the appropriate development of the community to deliver better services and escape from the spiral of malnutrition, infection, disease and poverty (Schaible UE \& Kaufmann SHE, 2007).

There is an economic cost also associated to overweight and obesity and non communicable diseases, arisen primarily from the increased spending on health care and reduced productivity. The cost of all obesity- and overweight-related non communicable diseases was estimated at US $\$ 1.4$ trillion in 2010 (WHO, 2011).

\subsection{FARMING AND HEALTH}

Agriculture presents opportunities and risks to health, as it is linked to the main causes of death and disease, and thus also to the main ways of preventing them: malnutrition, infectious diseases and chronic diseases (Lipton \& De Kadt, 1988).

The interlinks between agriculture and health are complex as they happen all along the supply chain through different intermediary processes and affecting different health outcomes and parts of the health systems (Hawkes C \& Ruel M, 2006). For the purpose of this paper, we will simplify the framework and focus on three parts of the agricultural supply chain (producers, systems and outputs) and their effects on health (as depicted in Figure 1).

Figure 1. Conceptual framework of the links between agriculture and health. Adapted from Hawkes et al, 2006.

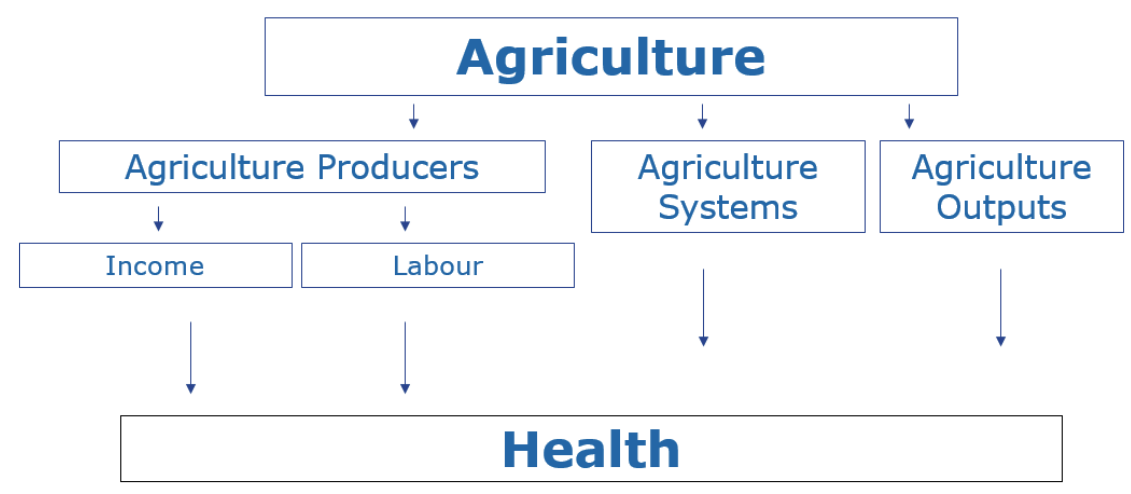

The link between agricultural producers and health is mainly mediated by income and labour. Workers in agriculture (as farmers of labourers) generate income for their household, which allows their families to purchase and access food, water and other health related services. The distribution of income and who controls it in the household can also have an effect on health, as depending on the context men and women may not have the same priorities in terms of family expenses. Due to its specificities, the agricultural labour can affect health in different ways: (a) by the energy expenditure it implies as hard physical work which can affect the balance between dietary energy intake and expenditure; (b) by the limitation on the time available for child care and food preparation in certain agricultural seasons, which can affect the family nutritional and health status, and (c) by exposure and spread of specific diseases (Hawkes C \& Ruel M, 2006). Farming exposes producers to different health hazards including zoonoses (diseases spread by livestock) and pesticide poisoning (Cole D, 2006). And agricultural employment can also contribute to the spread of 
infectious diseases such as HIV/AIDS due to its influence on migration patterns and the search of alternative income generating activities.

On the other direction, agricultural communities can be adversely affected by health as ill agricultural workers have reduced capacity to work and generate food and income to provide their families and communities in a similar way to the food security-health vicious cycle. For agriculture in particular, this relationship was evidenced by the devastating effects of HIV/AIDS in agricultural communities of Sub Saharan Africa (Hawkes C\& Ruel M, 2006).

\subsection{AGRICULTURAL SYSTEMS AND HEALTH}

Agricultural systems vary greatly in terms of extension, crops cultivated, technologies used and land ownership, and thus its effects on health will vary according to the combination of those characteristics. For example, in livestock production the contact with different animals will increase the risk to specific zoonoses, which will be absent in other type of agricultural systems.

One of the intermediary process between agricultural systems and health is the environmental change that agricultural practices can create, such as changing ecosystems which attract vector borne diseases (Hawkes C\& Ruel M, 2006).

At the same time, poor health reduces the ability of producers to innovate, invest in and operationalize changes in agricultural systems, including changes that promote health (Lipton \& De Kadt, 1988).

A good example of this bidirectional association is the development of water resources for agriculture (irrigation, dams, ponds for livestock and fish, etc.) that can benefit health by increasing agricultural production and income generation, and by delivering water for hygiene and sanitation practices, among others. On the other hand, they can create environments suitable for the propagation of insect vectors favouring and/or intensifying the transmission of water-related vector-borne diseases, such as malaria (Van der Hoek W, 2004).

Additionally, health related issues can drive agriculture policies and crops prioritization, as in the case of concerns about foodborne illnesses or diet-related chronic diseases which can reduce or create demand for certain foods over others (Hawkes C \& Ruel M, 2006).

\subsection{BIODIVERSITY AND HEALTH}

There is scarcity of evidence directly relating biodiversity and health outcomes, but numerous studies have found positive relationships between diversified farming systems and dietary diversity at household and individual level, which can contribute to better nutrition and consequently healthier status. Also, diversified production in home gardens have also shown positive impacts on nutrition in different countries (High Level Panel of Experts on Food Security and Nutrition, 2019).

From another perspective, the World Health Organization defines health as not simply the absence of illness, but a state of complete physical, mental and social well-being. Biodiversity can contribute to those different aspects by sustaining the functioning of the ecosystems on which we depend for our food and fresh water; by regulating climate, and by providing recreational benefits, among others. 


\section{A POSITIVE APPROACH TO TACKLE HUNGER AND POOR HEALTH: THE SYSTEMIC APPROACH}

This note has focused on the independent relationship of each of the SDG2 targets with health. However, most of the times all these negative conditions (food insecurity, malnutrition, poor working conditions and agricultural systems that damage the environment in detrimental to health and biodiversity) co-exist within the same populations and at the same time. Thus, a systemic approach is needed, in order to tackle food systems that ensure biodiversity and resilience of agricultural food producers, while safeguarding small scale food producers work conditions and that is oriented to reduce local food insecurity and to provide nutritious and healthy foods for all (High Level Panel of Experts on Food Security and Nutrition, 2017). A food systems approach considers the food system in its totality, taking into account all the elements, their relationships and related effects. It is not restricted to one single sector or discipline. It widens the framing and analysis of a particular issue as the result of complex matrix of interlinked activities and feedbacks, and it considers all relevant causal variables of a problem and all social, environmental, and economic impacts of the solutions to achieve transformational systemic changes (FAO, 2018).

Moreover, food systems are much broader than the food related processes described in this note ${ }^{6}$, and interlinkages with health happen in many other parts of the food system (encompassing production, processing, marketing and purchase of food, as well as consumer behaviours, resources and institutions). Thus, in order to tackle zero hunger and global health we need an approach with a broad perspective on food systems and health interactions, as the one proposed by the EU "Farm to Fork" strategy (European Commission, 2020b). This strategy points to new and better balance of nature, food systems and biodiversity to protect people's health and well-being while increasing resilience and fair economic return in the food chain.

\section{CONCLUSIONS}

All targets of SDG2 (zero hunger) show direct effects on global health and are at the same time affected by health in one way or another. Food insecurity and malnutrition, but also food producers working conditions, agricultural systems and biodiversity all have effects on health outcomes.

These results encourage the inclusion of food security and agriculture as important social determinants of health, to take into account in the design of new approaches to tackle global health.

Moreover, the interlinkages between food, nutrition and health extend well beyond the dimensions explored in this note, thus we advocate for a broad systemic approach aiming at health and sustainable food systems, as the one proposed by the EU "Farm to Fork" strategy.

\footnotetext{
${ }^{6} \mathrm{FAO}$ defines the food system as encompassing the entire range of activities involved in the production, processing, marketing, consumption and disposal of goods that originate from agriculture, forestry or fisheries, including the inputs needed and the outputs generated at each of these steps. Food systems also involve the people and institutions that initiate or inhibit change in the system as well as the socio-political, economic and technological environment in which these activities take place" (FAO, 2013a).
} 


\section{BIBLIOGRAPHY}

- 2018 Global Nutrition Report: Shining a light to spur action on nutrition. (2018). Development Initiatives.

- 2020 Global Nutrition Report: Action on equity to end malnutrition. (2020). Development Initiatives.

- Chilton M, \& Booth S. (2007). Hunger of the Body and Hunger of the Mind: African American Women's Perceptions of Food Insecurity, Health and Violence. Journal of Nutrition Education and Behavior, 39(3).

- Cole D. (2006). Occupational hazards of agriculture. In Understanding the links between agriculture and health. International Food Policy Research Institute.

- Collins, S., Dent, N., Binns, P., Bahwere, P., Sadler, K., \& Hallam, A. (2006). Management of severe acute malnutrition in children. The Lancet, 368(9551), 1992-2000. https://doi.org/10.1016/S01406736(06)69443-9

- Committee on World Food Security. (2016). Connecting Smallholders to Markets. CFS 46. http://www.fao. org/cfs/home/activities/smallholders/en/

- Dangour AD, Mace G, \& Shankar B. (2017). Food systems, nutrition, health and environment. The Lancet, 1(April).

- Darnton-Hill, I., Nishida, C., \& James, W. (2004). A life course approach to diet, nutrition and the prevention of chronic diseases. Public Health Nutrition, 7(1a), 101-121. https://doi.org/10.1079/PHN2003584

- Dewey,K.G., \&Begum,K.(2011).Long-termconsequences of stunting inearlylife:Long-termconsequences of stunting. Maternal \& Child Nutrition, 7, 5-18. https://doi.org/10.1111/j.1740-8709.2011.00349.x

- European Commission. (2020a). Bringing nature back into our lives. EU 2030 Biodiversity strategy factsheet. https://ec.europa.eu/commission/presscorner/detail/en/fs_20_906

- European Commission. (2020b). A Farm to Fork Strategy for a fair, healthy and environmentally-friendly food system. Communication from the Commission to the European Parliament, the Council, the European Economic and Social Committee and the Committee of the Regions. (COM(2020( 381 final). https://ec.europa.eu/info/ sites/info/files/communication-annex-farm-fork-green-deal_en.pdf

- FAO. (2004). What is happening to agrodiversity? In Building on Gender, Agrobiodiversity and Local Knowledge.

- Food and Agriculture Organization of the United Nations. (2019). The state of food security and nutrition in the world: safeguarding against economic slowdowns and downturns.

- Hawkes C, \& Ruel M. (2006). The links between agriculture and health: an intersectoral opportunity to improve the health and livelihoods of the poor. Bulletin of the World Health Organization, 84, 985-991.

- High Level Panel of Experts on Food Security and Nutrition. (2017). Nutrition and food systems (HLPE Report No. 12). Committee on World Food Security.

- High Level Panel of Experts on Food Security and Nutrition. (2019). Agroecological and other innovative approaches for sustainable agriculture and food systems that enhance food security and nutrition. Committe on World Food Security.

- IFAD \& UNEP. (2013). Smallholders, food security, and the environment. IFAD \& UNEP.

- Lipton, M., \& De Kadt, E. J. (1988). Agriculture-health linkages. World Health Organization; WHO Publication Center USA [distributor].

- Lowder SK, Sánchez MV, \& Bertini R. (2019). Farms, family farms, farmland distribution and farm labour: What do we know today? (FAO Agricultural Development Economics Working Paper 19=08). FAO. 
- Maas Wolfenson KD. (2013). Coping with the food and agriculture challenge: smallholders'agenda. Preparations and outcomes of the 2012 United Nations Conference on Sustainable Development (Rio +20). FAO.

- Melchior M, Chastang JF, Falissard B, Galéra C, Tremblay RE, \& Côté SM. (2012). Food Insecurity and Children's Menatl Health: A Prospective Birth Cohort Study. PLoS ONE, 7(12), e52615.

- Prendergast, A. J., \& Humphrey, J. H. (2014). The stunting syndrome in developing countries. Paediatrics and International Child Health, 34(4), 250-265. https://doi.org/10.1179/2046905514Y.0000000158

- Schaible UE, \& Kaufmann SHE. (2007). Malnutrition and infection: Complex mechanisms and global impacts. PLoS Medicine, 4(5), e115.

- FAO. (2018). Sustainable food systems. Concept and framework. Food and Agriculture Organization of the United Nationa.

- UNICEF. (1990). Strategy for Improved Nutrition of Children and Women in Developing Countries. UNICEF.

- UNICEF, WHO, \& World Bank. (2020). Levels and trend in child malnutrition. UNICEF/WHO/World Bank Group Joint Child Malnutrition Estimates. Key finding of the 2020 edition. data.unicef.org/nutrition

- Van der Hoek W. (2004). Malaria and Agriculture. Acta Tropica, 89(2), 95-264.

- WHO. (1995). Physical Status: the Use and Interpretation of Anthropometry. Report of a WHO Expert Committee. (No. 854; Technical Report Series). http://www.who.int/childgrowth/publications/physical_status/en/

- WHO. (2000). Obesity: Preventing and managing the global epidemic (No. 894; WHO Technical Report Series).

- WHO. (2011). Global status report on noncommunicable diseases 2010. World Health Organization.

- WHO. (2020). Nutrition. https://www.who.int/health-topics/nutrition

- Willett, W., Rockström, J., Loken, B., Springmann, M., Lang, T., Vermeulen, S., Garnett, T., Tilman, D., DeClerck, F., Wood, A., Jonell, M., Clark, M., Gordon, L. J., Fanzo, J., Hawkes, C., Zurayk, R., Rivera, J. A., De Vries, W., Majele Sibanda, L., ... Murray, C. J. L. (2019). Food in the Anthropocene: the EAT-Lancet Commission on healthy diets from sustainable food systems. The Lancet, 393(10170), 447-492. https:// doi.org/10.1016/S0140-6736(18)31788-4 